\title{
Diamond deposition on modified silicon substrates: Making diamond atomic force microscopy tips for nanofriction experiments
}

\author{
Citation for published version (APA): \\ Tanasa, G., Kurnosikov, O., Flipse, C. F. J., Buijnsters, J. G., \& Enckevort, van, W. J. P. (2003). Diamond \\ deposition on modified silicon substrates: Making diamond atomic force microscopy tips for nanofriction \\ experiments. Journal of Applied Physics, 94(3), 1699-1704. https://doi.org/10.1063/1.1590058
}

DOI:

10.1063/1.1590058

Document status and date:

Published: 01/01/2003

\section{Document Version:}

Publisher's PDF, also known as Version of Record (includes final page, issue and volume numbers)

\section{Please check the document version of this publication:}

- A submitted manuscript is the version of the article upon submission and before peer-review. There can be important differences between the submitted version and the official published version of record. People interested in the research are advised to contact the author for the final version of the publication, or visit the DOI to the publisher's website.

- The final author version and the galley proof are versions of the publication after peer review.

- The final published version features the final layout of the paper including the volume, issue and page numbers.

Link to publication

\footnotetext{
General rights

- You may freely distribute the URL identifying the publication in the public portal. follow below link for the End User Agreement:

www.tue.nl/taverne

\section{Take down policy}

If you believe that this document breaches copyright please contact us at:

openaccess@tue.nl

providing details and we will investigate your claim.
}

Copyright and moral rights for the publications made accessible in the public portal are retained by the authors and/or other copyright owners and it is a condition of accessing publications that users recognise and abide by the legal requirements associated with these rights.

- Users may download and print one copy of any publication from the public portal for the purpose of private study or research.

- You may not further distribute the material or use it for any profit-making activity or commercial gain

If the publication is distributed under the terms of Article 25fa of the Dutch Copyright Act, indicated by the "Taverne" license above, please 


\title{
Diamond deposition on modified silicon substrates: Making diamond atomic force microscopy tips for nanofriction experiments
}

\author{
G. Tanasa, O. Kurnosikov, and C. F. J. Flipse ${ }^{a)}$ \\ Department of Applied Physics and Chemical Engineering, Molecular Materials and Nanosystems, \\ Center for NanoMaterials, Eindhoven University of Technology, Den Dolech 2, 5600 MB Eindhoven, \\ The Netherlands \\ J. G. Buijnsters \\ NSRIM, Department of Applied Physics, University of Nijmegen, Toernooiveld 1, 6525 ED Nijmegen, \\ The Netherlands \\ W. J. P. van Enckevort \\ NSRIM, Department of Solid State Chemistry, University of Nijmegen, Toernooiveld 1, 6525 ED Nijmegen, \\ The Netherlands
}

(Received 12 March 2003; accepted 19 May 2003)

\begin{abstract}
Fine-crystalline diamond particles are grown on standard Si atomic force microscopy tips, using hot filament-assisted chemical vapor deposition. To optimize the conditions for diamond deposition, first a series of experiments is carried out using silicon substrates covered by point-topped pyramids as obtained by wet chemical etching. The apexes and the edges of the silicon pyramids provide favorable sites for diamond nucleation and growth. The investigation of the deposited polycrystallites is done by means of optical microscopy, scanning electron microscopy and micro-Raman spectroscopy. The resulting diamond-terminated tips are tested in ultra high vacuum using contact-mode atomic force microscope on a stepped surface of sapphire showing high stability, sharpness, and hardness. (C) 2003 American Institute of Physics.
\end{abstract}

[DOI: $10.1063 / 1.1590058]$

\section{INTRODUCTION}

Recent experiments dedicated to friction between atomically flat surfaces and an atomic force microscope (AFM) tip, show that wearless friction is possible and, moreover, the classical law of friction is not valid anymore for contact areas in the range of several square nanometers. ${ }^{1-4}$ Unfortunately, the tips of the standard silicon or silicon nitride cantilevers often get damaged either due to snapping into contact or scanning with increasing load. Therefore, the results of friction experiments are affected with uncertain parameters, which cannot be accounted for by a simple model. Dealing with an "ideal" model system, single-crystalline sample and tip with known and stable characteristics should be used.

The use of hard materials, such as diamond, at the contact points for friction experiments on the nanometer scale could provide a stable contact area with a controllable interatomic interaction between the tip and the surface during sliding. In spite of the fact that, due to its extraordinary properties, diamond surfaces and diamond-coated substrates have been under intensive investigation for macroscopic tribology ${ }^{5,6}$ only a few reports concerning the nanometerscale friction on this material can be found. ${ }^{3,4,7}$

In earlier approaches, hard tips for AFM and scanning tunneling microscopy (STM) were fabricated from bulk dia-

a) Author to whom correspondence should be addressed; electronic mail: c.f.j.flipse@tue.nl mond by fracturing, grinding or polishing. ${ }^{8-10}$ The developments in the field of chemical vapor deposition (CVD) techniques provided a very flexible tool for obtaining diamond layers and microcrystals with a large range of sizes and properties. ${ }^{5,6}$ Compared to other methods, for example the high-pressure-high-temperature method, the crystallites can be deposited on a wide range of materials, like $\mathrm{Si}, \mathrm{Mo}$, and $\mathrm{Cr}$, with more or less complex shapes. For instance, individual diamond crystals or films were deposited on etched tungsten wires, silicon whiskers and tips to be used for SPM and field emission experiments. ${ }^{11-13}$ Methods based on a moulding technique were also proposed for creating alldiamond or silicon cantilevers tips with very sharp diamond termination. ${ }^{14-16}$

In this article we present a method of growing individual diamond polycrystallites on the apex of a standard AFM cantilever tip. First, we searched for the optimal conditions of the CVD synthesis in order to obtain a preferential nucleation of diamond grains on the edges and tops of pyramids obtained by wet chemical etching of single-crystalline silicon substrates. Using this information we then demonstrated diamond growth at the very apex of the silicon tips of commercially available AFM cantilevers. Raman spectroscopy as well as scanning electron microscopy (SEM) reveals information about the structure, quality and shape of the deposited diamond. The resulting cantilevers have been used in friction-mode AFM experiments and showed a reliable behavior of the diamond-terminated tips. 


\section{EXPERIMENTAL PROCEDURE}

Prior to the CVD deposition on real AFM cantilevers, we studied the nucleation and growth of diamond crystallites on specially fabricated silicon substrates having an array of pyramidal hillocks in order to find the best conditions of deposition. The point-topped pyramids were obtained by wet chemical etching of polished (100) silicon plates in aqueous $\mathrm{KOH}$ solutions. ${ }^{17-20}$ The setup used for etching the silicon substrates consisted of thermostated $\left( \pm 1^{\circ} \mathrm{C}\right)$ small Teflon beakers containing the $\mathrm{KOH}$ etching solutions. The samples used in these experiments were $p$-type boron doped (100) Si wafers $(14-22 \Omega \mathrm{cm})$. Before etching, the samples were chemically cleaned using an HF dip and subsequent rinsing in de-ionized water. Then, the surface of the Si substrate was scratched using a diamond scribing tool, after which the silicon surface displayed a net of parallel, equidistant scratched lines in two perpendicular directions. The distance between two neighboring lines varied from 0.2 to $0.8 \mathrm{~mm}$. The aqueous $\mathrm{KOH}$ etchant solutions had concentrations between 20 and $40 \mathrm{wt} \% \mathrm{KOH}$. Etching was carried out for a period of 60-180 min at temperatures between 70 and $90^{\circ} \mathrm{C}$. After the chemical etching, the samples were rinsed using de-ionized water.

Diamond deposition was carried out in a conventional hot-filament-assisted CVD reactor as described elsewhere. ${ }^{21}$ In all deposition runs, the substrate temperature was fixed at $750{ }^{\circ} \mathrm{C}$ for deposition times in the range of $1-6 \mathrm{~h}$. The $\mathrm{TaC}$ filament temperature was kept constant at $2100 \pm 20^{\circ} \mathrm{C}$ as measured with an optical pyrometer. The $\mathrm{CH}_{4}: \mathrm{H}_{2}$ volume ratio was fixed at $0.5 \%$, keeping the total pressure in the range of 50-60 mbar and the total flow rate at 300 standard $\mathrm{cm}^{3} \mathrm{~min}^{-1}$. The pretreated/etched Si wafers $\left(1.5 \times 1.5 \mathrm{~cm}^{2}\right)$ were used as substrates.

When the best conditions for CVD deposition on etched Si pyramids were found, hot-filament-assisted CVD (HFCVD) runs were performed on commercially available $\mathrm{Si}$ AFM tips. Silicon chips (NSC 12 series, MikroMasch) ${ }^{22}$ with six rectangular cantilevers were used. All cantilevers have an $\mathrm{Al}$ coating on the backside for better reflectivity. The three longer cantilevers of the set are suitable for friction (lateral) force measurements. In the HF-CVD reactor, the chips containing the $\mathrm{Si}$ cantilevers were placed on small sapphire plates in order to provide a good heat transfer. In all runs, the above-mentioned deposition parameters were kept unchanged except for the deposition duration of $4 \mathrm{~h}$, which was found to be the most suitable.

In order to enhance diamond nucleation, prior to the deposition run some of the silicon chips were immersed in a suspension consisting of ethyl alcohol and diamond powder (4-6 $\mu \mathrm{m}$ grid size) for $3 \mathrm{~min}$. Moreover, a few of them were ultrasonically shaken in the suspension for 30-60 s. The results for the two types of "seeded" tips were compared to those obtained for the untreated cantilevers.

Micro-Raman spectroscopy was performed using an $\mathrm{Ar}^{+}$ ion laser $(514.5 \mathrm{~nm})$ with an output power of $50 \mathrm{~mW}$ and a focused laser beam diameter of about $2 \mu \mathrm{m}$ (Renishaw System 1000). The Raman spectra were taken in the 900-2400

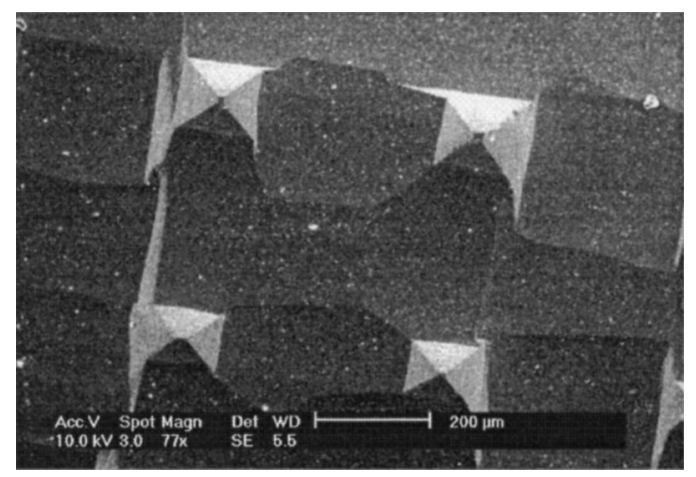

FIG. 1. SEM image of the pyramids obtained after wet chemical etching in aqueous $\mathrm{KOH}$ solution.

$\mathrm{cm}^{-1}$ range, selecting the investigated deposits by optical microscopy.

The shape, microstructure, and distribution of the diamond grains on the Si substrate were determined by means of SEM (Philips XL 30 ESEM FEG). It is known that the electron beam used in the SEM technique can deposit thin carbon contamination layers or even graphitise the diamond slightly; therefore Raman measurements were performed before investigating the sizes and shapes of the deposited crystals by means of SEM.

The diamond-terminated AFM tips obtained in the above-mentioned way were tested using an Omicron variable temperature-ultrahigh vacuum (VT-UHV) AFM STM. As an object a stepped (0001) sapphire substrate was used and topographic, normal force and lateral (friction) force maps were recorded in contact-mode AFM. The base pressure inside the chamber was $6 \times 10^{-11} \mathrm{mbar}$ and all the measurements were carried out at room temperature.

\section{RESULTS AND DISCUSSION}

\section{A. Morphology of diamond deposits on etched silicon pyramids}

After chemical etching of the scratched Si wafers, SEM images of the samples display a uniform distribution of square-based pyramids with sharp facet edges and apexes (Fig. 1). The size of the square base is about 100 $\times 100 \mu \mathrm{m}^{2}$, after $2 \mathrm{~h}$ of etching.

The typical distance between the bases of two neighboring pyramids is approximately $300 \mu \mathrm{m}$ and the density of pyramids is in the order of $400-450$ pyramids $/ \mathrm{cm}^{2}$. When increasing the period of etching, the pyramid shape becomes less sharp and the distribution of the elevations on the silicon surface is not homogeneous anymore. It was observed that the etching parameters are not necessarily uniquely defined. For instance, a specific size and shape of the pyramids were achieved using a given etchant concentration and duration, but the same result could be obtained by performing the etching using a higher etchant solution concentration, but for a shorter period.

On the pretreated/etched $\mathrm{Si}$ wafers diamond deposition runs using hot-filament-assisted CVD have been performed. SEM images of samples corresponding to a deposition time of less than $2 \mathrm{~h}$ do not show diamond grains on the silicon 

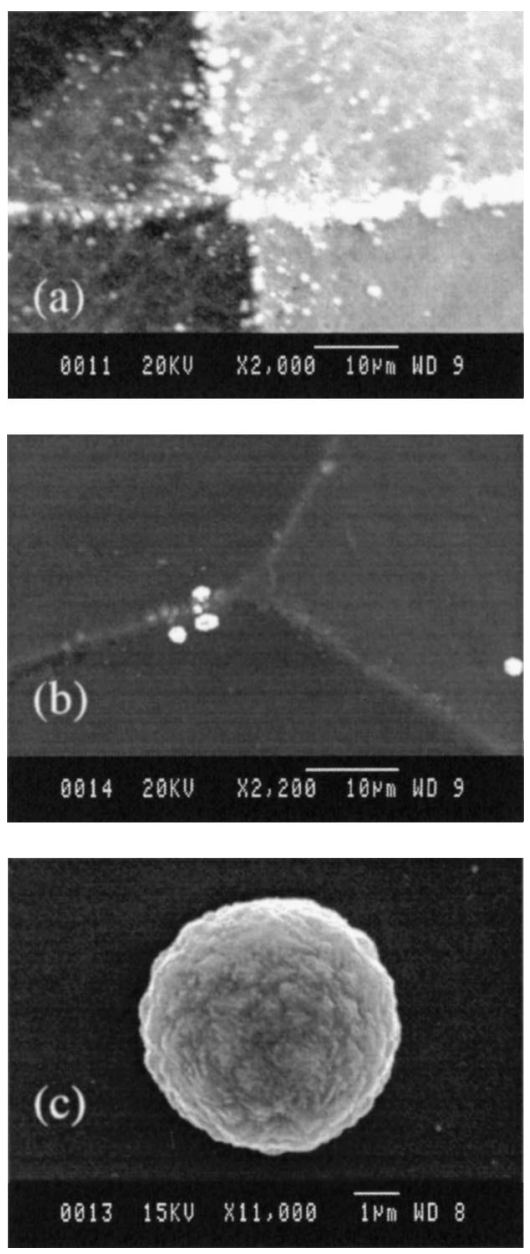

FIG. 2. SEM images showing deposited grains on the top and facet edges of the Si etch pyramids: (a) large number of diamond particles on the edges and apex of a pyramid; (b) a few isolated crystals near to pyramid tip; and (c) high magnification micrograph showing the ball-shaped nature of many diamond polycrystallites.

pyramid apexes. After $4 \mathrm{~h}$ of deposition, most of the pyramids exhibit a large number (100-150) of small crystals on the apexes and edges [Fig. 2(a)]. The size of the grains varied between 1 and $3 \mu \mathrm{m}$. Most of the grains are polycrystalline and show a spherical or blunted shape. Nevertheless single crystalline or twinned diamond particles could also be observed in about $20 \%$ of the cases.

For deposition times between 4 and $6 \mathrm{~h}$, SEM and optical microscope images show the presence of crystallites on the edges and the apexes of the pyramids in $20 \%-25 \%$ of the cases. The size of the polycrystals was on the order of 5-6 $\mu \mathrm{m}$ and the spherical shape was more or less similar for all the deposits [Fig. 2(c)]. The microstructure of the grown particles is polycrystalline, with sizes of the grains ranging from five to tens of nanometers. This type of ball-shaped crystallites is typical for CVD growth conditions of higher carbon supersaturation. ${ }^{23}$

To investigate the quality and structure of the deposited particles, further investigations using micro-Raman spectroscopy were carried out. This analysis technique is suitable, because it can distinguish clearly between diamond, graphitic, and other carbon phases. Another important reason is its spatial resolution (focused laser beam diameter of about 2

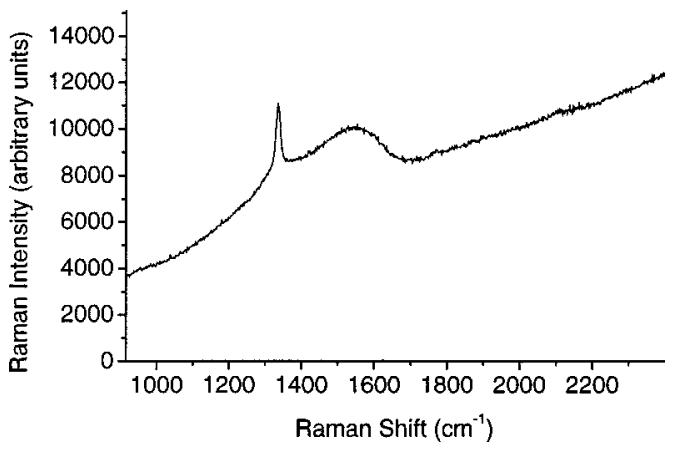

FIG. 3. Typical Raman spectrum of the deposited diamond crystallites on the etched silicon substrates.

$\mu \mathrm{m})$, which is comparable to the sizes of the deposited elements on the substrate. Raman spectroscopy is very sensitive in distinguishing the different forms of crystalline and amorphous carbon. Raman spectra of stress-free, crystalline diamond show a single, sharp line at $1332 \mathrm{~cm}^{-1}$. Graphitic carbon gives two peaks: the so-called $G$ peak centered at 1550 $\mathrm{cm}^{-1}$ is the Raman line of a perfect graphite crystal, while the so-called $D$ peak centered at $1350 \mathrm{~cm}^{-1}$ indicates disorder. The $D$ mode is a common characteristic of all disordered graphitic carbons (coals, glassy carbon, etc), which intensity relative to the $1550 \mathrm{~cm}^{-1}$ peak, varies inversely with the size of the graphitic microstructures. ${ }^{6,24-30}$ Finally, amorphous carbon generally gives a broad band centred on about 1500 $\mathrm{cm}^{-1}$.

The investigated deposits were selected by using the optical microscope fitted with the Raman spectrometer. Then, the laser light was focused on small crystals having various sizes and positions on the silicon substrate.

The typical Raman spectra of the deposited crystallites exhibit a sharp diamond peak positioned between 1332.8 and $1336.4 \mathrm{~cm}^{-1}$ with full width at half maximum values between 15 and $20 \mathrm{~cm}^{-1}$ (Fig. 3). A broadband $\left(\sim 200 \mathrm{~cm}^{-1}\right)$ corresponding to nondiamond forms of carbon ( $s p^{2}$ bonded), centered on $1552 \mathrm{~cm}^{-1}$ is present as well. The height ratio of the diamond peak to this band varies between 1.1 and 1.9. Considering the large Raman scattering cross section ${ }^{27}$ for $s p^{2}$ carbon bonds as compared to diamond, these values show good quality diamond and the presence of a small amount of other carbon phases.

\section{B. Diamond deposition on standard silicon tips}

After finding the appropriate deposition parameters, diamond was grown on standard silicon tips. Deposition runs of $4 \mathrm{~h}$ were carried out in all cases. As a general feature, optical microscopy and SEM pictures reveal the tendency of the crystals to grow on the apexes and edges of the pyramidal tips as well as on the edges of the rectangular cantilevers (Figs. 4, 5, and 6). However, for the untreated chips and those that were seeded by immersion in a diamond powder/ ethanol suspension, the results were unsatisfactory. On the other hand, for the chips that have been ultrasonically shaken in the diamond suspension, the number of the grown crystals 

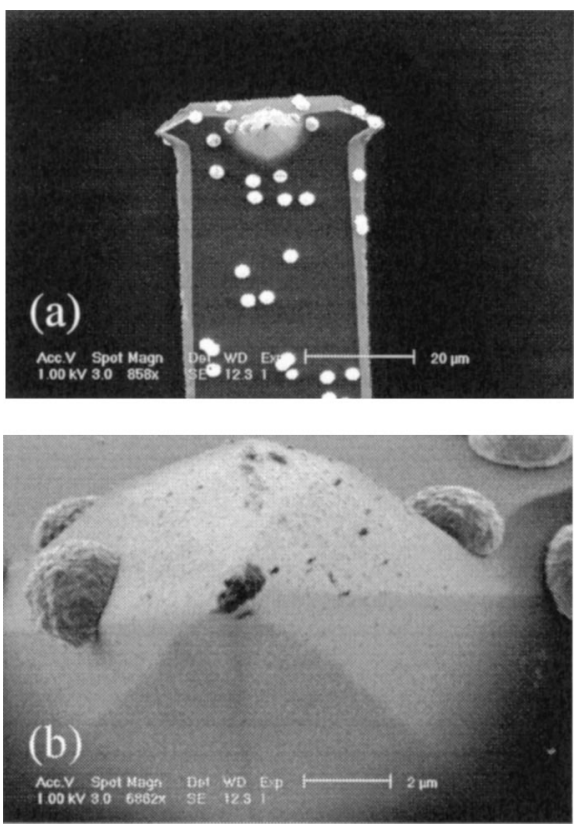

FIG. 4. Diamond growth on standard Si tips without pretreatment: (a) overview showing cantilever plus tip and (b) detail of tip; the black spot at the tip is not diamond but contamination.

is much larger than on the nonpretreated ones. Moreover, in this case $80 \%-90 \%$ of the pyramidal Si tips contain a diamond crystal at the very apex (Fig. 6).

The size of the deposited crystals varies from 1.5 to 2.3 $\mu \mathrm{m}$. Sometimes, for the seeded cantilevers, even bigger deposits are observed (diameters larger than 3-4 $\mu \mathrm{m}$ ). We attribute this either to the presence of the seeding powder on the cantilevers with further diamond growth on top of it, or to coalescent crystals. The microstructure of the deposited particles is depicted in Fig. 7, which shows that they are spherical polycrystalline aggregates consisting of numerous crystallites of a few $10 \mathrm{~nm}$ in size.

The best quality diamond polycrystals are grown after the ultrasonic treatment. The diamond peak is positioned in the range of $1332.8-1334.9 \mathrm{~cm}^{-1}$ and the ratio diamond/ nondiamond peak heights in the spectra ranged from 1.02 to 1.67 , with the maximum value corresponding to the situation when the deposition was performed after ultrasonic shaking in the seeding suspension (see Fig. 8).

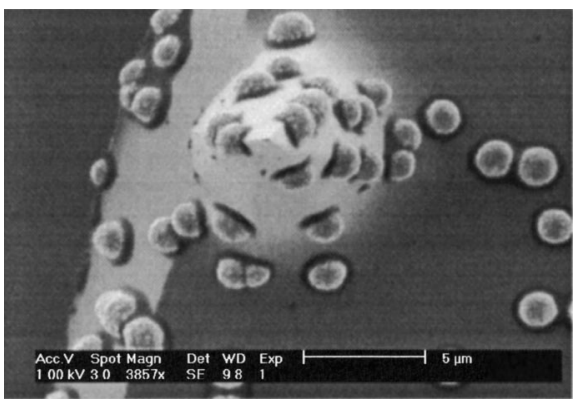

FIG. 5. Deposition after seeding the standard Si tips by immersing in diamond powder/ethanol suspension, leads to an enhanced density of diamond nuclei.
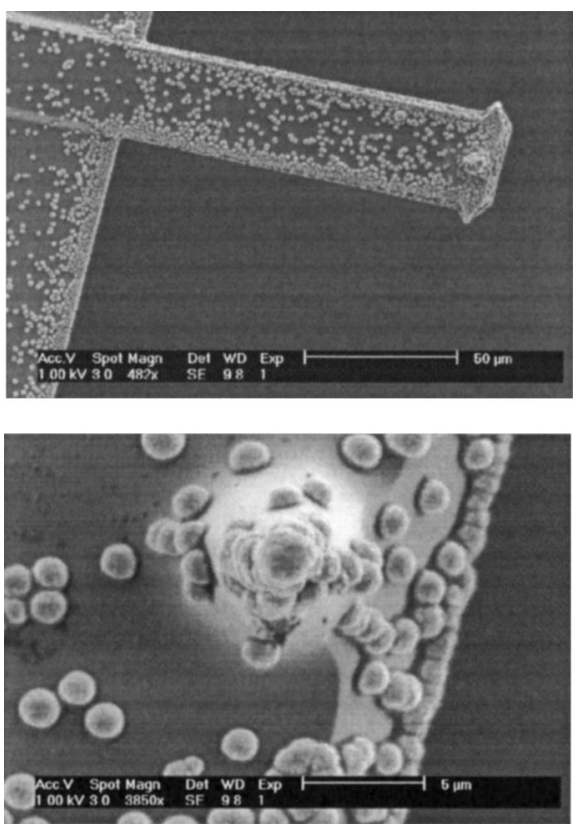

FIG. 6. After ultrasonic shaking in the diamond/ethanol suspension a higher density of crystallites and crystal growth at the very apexes of the tips are obtained. In this way suitable diamond-tipped AFM probes can be produced.

\section{Diamond-terminated cantilever tests in ultrahigh vacuum}

The performances of the Si tips having diamond crystals at the apex were tested in UHV, using a VT-UHV AFM STM. After the deposition, the resonance frequencies of the cantilevers were checked and showed no major differences, still being within the range of values given by the producer. For nanofriction (lateral force) measurements, only the long cantilevers of the Si chips were used, because of their small spring constant values.
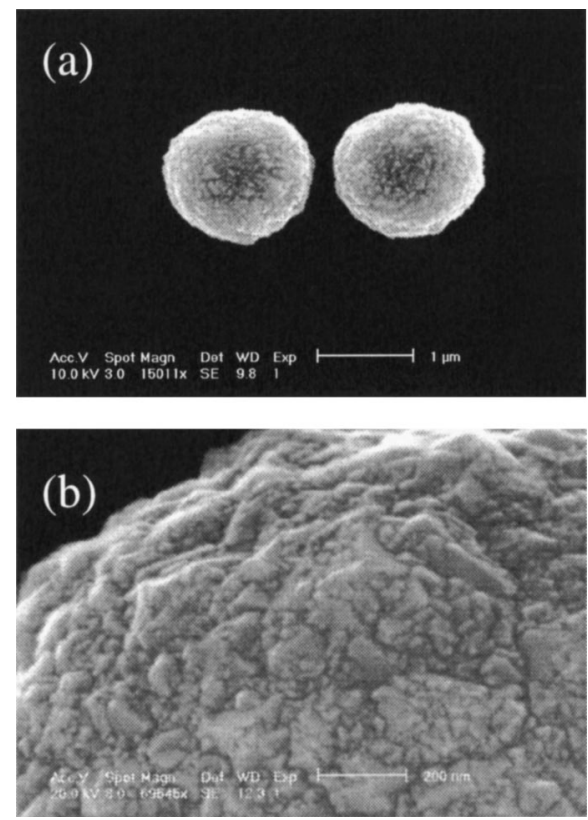

FIG. 7. SEM images of the deposited diamond particles (a) showing their polycrystalline microstructure in detail (b). 


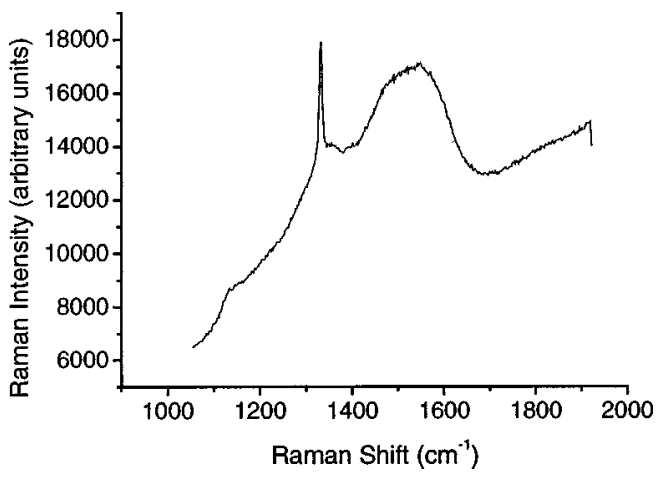

FIG. 8. Typical Raman spectrum for the crystals deposited on the standard silicon tips.

The presence of the crystals at the very apex of the tips was verified before and after the AFM scans by means of SEM, using a lower acceleration energy for the electrons (1 $\mathrm{kV}$ ) in order to avoid the destruction of diamond crystalline structure.

The scanning performances of the diamond-terminated tips have been investigated using a known-topography object. The sample chosen was the stepped (0001) sapphire surface. Typical ways of preparing the surface and the subsequent topography are described elsewhere. ${ }^{31,32}$ Sapphire is a very hard material and therefore its vicinal (0001) stepped surface provides a very good tool for checking the adhesion of the diamond deposits to the silicon tips while scanning in contact-mode AFM at different loads. Moreover, the presence of the terraces and steps can give us precise information about the achieved lateral resolution.

It is important to mention that when focusing the laser beam on the backside of the cantilevers with diamond deposits, the resulting intensity on the four-quadrant photodiode is much lower (factor of 5-6) than that achieved in the case of regular cantilevers. This is not surprising because diamond nucleation normally occurs on both sides of the cantilevers, producing a scattering of the focused light. Moreover, the heating in the HF-CVD reactor definitely affected the reflectivity and maybe the flatness of the Al coating, as SEM investigation revealed. One should realize that the temperature of deposition $\left(750^{\circ} \mathrm{C}\right)$ exceeds the melting point of $\mathrm{Al}$, which is $660{ }^{\circ} \mathrm{C}$. Nevertheless, good quality images could be obtained in the contact-mode regime.

The AFM micrographs shown in Fig. 9 are recorded in contact-mode and exhibit topographic, normal force and lateral (friction) force maps of the same $2 \times 2 \mu \mathrm{m}^{2}$ area of sapphire surface. Topographic images reveal that the sample surface is covered with faceted steps with heights ranging from 2 to $6 \mathrm{~nm}$ and the terraces are several $100 \mathrm{~nm}$ wide. The zigzag shape of the step edges is very clearly visible on both normal and friction force windows.

Although at first sight the diamond termination of the $\mathrm{Si}$ tips seems rather big and blunt, the part of the diamond particle (i.e., a corner of one of the nanocrystallites in the aggregate) really in "contact" with the scanned surface is extremely small and sharp. From the resulting good quality of the scan images of the sapphire steps we can estimate the tip radius of curvature to be between 10 and $20 \mathrm{~nm}$, which is
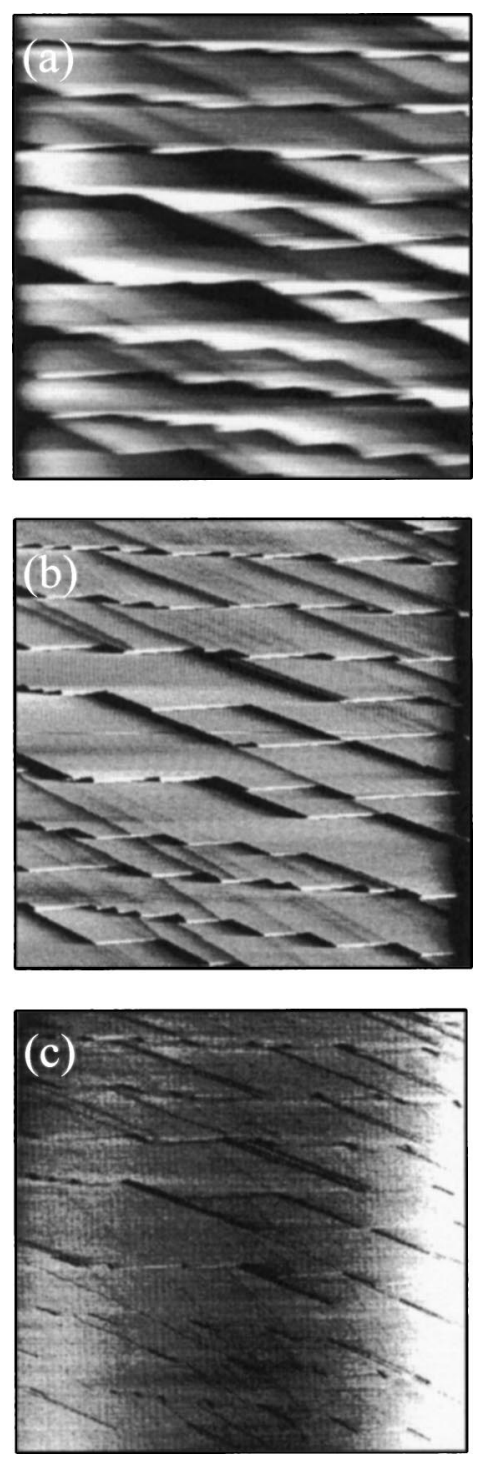

FIG. 9. Topography (a), normal force (b), and friction (lateral) force (c) maps in contact mode AFM of a zigzag stepped surface of (0001) $\mathrm{Al}_{2} \mathrm{O}_{3}$. The applied load is $1 \mathrm{nN}$.

very good by AFM standards where typical radii are in the range of several tens of nanometers.

After scanning with increasing values of the load (up to $4 \mathrm{nN}$ ), the status of the tip was checked by means of SEM and no apparent damage of the diamond termination at the tip could be observed. The revealed substrate morphology did not change after hours of repeated scanning. This proves that the bonding of the deposited diamond to the silicon substrates is strong and no wear is present.

\section{CONCLUSIONS}

In this work we have demonstrated a method to produce diamond-terminated Si tips for contact-mode atomic force microscopy, by using HF-CVD.

The first step was to confirm the preferential growth of diamond crystals at the apex of pyramids on a silicon substrate in order to simulate diamond deposition on standard AFM tips. These point-topped pyramids, which were more or less homogeneously distributed on the silicon wafers, were 
obtained by wet chemical etching in aqueous $\mathrm{KOH}$ solutions. SEM and optical microscopy images proved that the apexes and the edges of the pyramids were favourable sites for the nucleation and further growth of diamond polycrystals.

After finding the optimum conditions for diamond growth, standard Si tips were used as substrates for HF-CVD of diamond.

The resulting AFM tips have been used in nano-friction measurements of a stepped surface of sapphire crystal showing reliable behavior, good stability, sharpness, and hardness of the diamond termination. Further friction measurements on various substrates using such diamond tips will be performed in the near future.

\section{ACKNOWLEDGMENTS}

The authors would like to thank G. Wijers and H. Dalderop for the technical assistance. This work was supported by the Dutch Foundation for Fundamental Research (FOM).

${ }^{1}$ R. W. Carpick, N. Agrait, D. F. Ogletree, and M. Salmeron, J. Vac. Sci. Technol. B 14, 1289 (1996).

${ }^{2}$ R. W. Carpick, N. Agrait, D. F. Ogletree, and M. Salmeron, Langmuir 12, 3334 (1996).

${ }^{3}$ M. Enachescu, R. J. A. van den Oetelaar, R. W. Carpick, D. F. Ogletree, C. F. J. Flipse, and M. Salmeron, Phys. Rev. Lett. 81, 1877 (1998).

${ }^{4}$ M. Enachescu, R. J. A. van den Oetelaar, R. W. Carpick, D. F. Ogletree, C. F. J. Flipse, and M. Salmeron, Tribol. Lett. 7, 73 (1999).

${ }^{5}$ R. E. Clausing, L. L. Horton, J. C. Angus, and P. Koidl, NATO ASI Ser., Ser. B 266, 17 (1991).

${ }^{6}$ K. E. Spear and J. P. Dismukes, Synthetic Diamond: Emerging CVD Science and Technology (Wiley-Interscience, New York, 1994).

${ }^{7}$ G. J. Germann, S. R. Cohen, G. Neubauer, G. M. McClelland, H. Seki, and D. Coulman, J. Appl. Phys. 73, 163 (1993).

${ }^{8}$ O. Marti, B. Drake, and P. Hansma, Appl. Phys. Lett. 51, 484 (1987).

${ }^{9}$ R. Kaneko and S. Oguchi, Jpn. J. Appl. Phys., Part 1 29, 11854 (1990).

${ }^{10}$ E. Visser, J. Gerritsen, W. van Enckevort, and H. Van Kempen, Appl. Phys. Lett. 60, 3232 (1992).
${ }^{11}$ G. Germann, G. McClelland, Y. Mitsuda, M. Buck, and H. Seki, Rev. Sci. Instrum. 63, 4053 (1992).

${ }^{12}$ N. Liu, Z. Ma, X. Chu, T. Hu, Z. Xue, and S. Pang, J. Vac. Sci. Technol. B 12, 1856 (1994).

${ }^{13}$ E. Givargizov, V. Zhirnov, A. Stepanova, E. Rakova, A. Kiselev, and P. Plekahnov, Appl. Surf. Sci. 87/88, 24 (1995).

${ }^{14}$ E. Oesterschulze, W. Scholz, C. Mihalcea, D. Albert, B. Sobisch, and W. Kulisch, Appl. Phys. Lett. 70, 435 (1997).

${ }^{15}$ W. Kulisch, A. Malave, G. Lippold, W. Scholz, C. Mihalcea, and E. Oesterschulze, Diamond Relat. Mater. 6, 906 (1997).

${ }^{16}$ C. Mihalcea, W. Scholz, A. Malave, D. Albert, W. Kulisch, and E. Oesterschulze, Appl. Phys. A: Mater. Sci. Process. A66, S87 (1998).

${ }^{17}$ S.-S. Tan, M. Reed, H. Han, and R. Boudreau, J. Micromech. Microeng. 4, 147 (1994).

${ }^{18}$ L. M. Landsberger, S. Naseh, M. Kahrizi, and M. Paranjape, J. Micromech. Systems 2, 107 (1996).

${ }^{19}$ J.-H. Liu, T. M. Betzner, and H. T. Henderson, J. Micromech. Microeng. 5, 18 (1995).

${ }^{20}$ A. J. Nijdam, E. van Veenendaal, H. M. Cuppen, J. van Suchtelen, M. L. Reed, J. G. E. Gardeniers, W. J. P. van Enckevort, E. Vlieg, and M. Elwenspoek, J. Appl. Phys. 89, 4113 (2001).

${ }^{21}$ W. J. P. van Enckevort, G. Janssen, W. Vollenberg, M. Chemin, L. J. Giling, and M. Seal, Surf. Coat. Technol. 47, 39 (1991); for more details see: G. Janssen, PhD thesis, University of Nijmegen, 1994.

${ }^{22}$ Martech Scientific Instruments, Eindhoven, The Netherlands.

${ }^{23}$ S. Buhlmann, E. Blank, R. Haubner, and B. Lux, Diamond Relat. Mater. 8, 194 (1999).

${ }^{24}$ A. M. Bonnot, Phys. Rev. B 41, 6040 (1990).

${ }^{25}$ L. H. Robins, E. N. Farabaugh, and A. Feldman, J. Mater. Res. 5, 2456 (1990).

${ }^{26}$ R. G. Buckley, T. D. Moustakas, L. Ye, and J. Varon, J. Appl. Phys. 66, 3595 (1989)

${ }^{27}$ R. E. Shroder and R. J. Nemanich, Phys. Rev. B 41, 3738 (1990).

${ }^{28}$ S. C. Sharma, M. Green, R. C. Hyer, C. A. Dark, T. D. Black, A. R. Chourasia, D. R. Chopra, and K. K. Mishra, J. Mater. Res. 5, 2424 (1990).

${ }^{29}$ C. P. Chang, D. L. Flamm, D. E. Ibbotson, and J. A. Mucha, J. Appl. Phys. 63, 1744 (1988).

${ }^{30}$ F. G. Celii, P. E. Pehrsson, H.-T. Wang, and J. E. Butler, Appl. Phys. Lett. 52, 2043 (1988).

${ }^{31}$ O. Kurnosikov, L. Pham Van, and J. Cousty, Surf. Sci. 459, 256 (2000).

${ }^{32}$ L. Pham Van, O. Kurnosikov, and J. Cousty, Surf. Sci. 411, 263 (1998). 